\title{
Endovascular treatment of cerebral aneurysms using the Woven EndoBridge technique in a single center: preliminary results
}

\author{
Aimee Lawson, BMBS, MRCS(Eng), Tony Goddard, MBChB, MRCP, FRCR, \\ Stuart Ross, MCh, FRCS(SN), Atul Tyagi, MBBS, FRCS(SN), \\ Kenan Deniz, MBBChir, MRCS, FRCS(NeuroSurg), and Tufail Patankar, MBBS, PhD \\ Leeds Teaching Hospitals NHS Trust, Leeds, United Kingdom
}

OBJECTIVE The Woven EndoBridge (WEB) is an innovative new technique for securing cerebral aneurysms. It is designed particularly for wide-necked bifurcation aneurysms that otherwise would be difficult to treat. There is a paucity of follow-up data in the literature due to the novelty of this technique. The authors reviewed their data from cases involving patients treated at Leeds General Infirmary with the WEB device. They assessed the safety and complication risk associated with the device and clinical and radiological follow-up outcomes in their patients. This is, to their knowledge, the first publication to include the new single-layer sphere device (WEB SLS) in addition to the original dual-layer (WEB DL) and the (nonsphere) single-layer (WEB SL) devices.

METHODS Data from 22 patients who underwent 25 WEB treatments were analyzed. Of the 25 WEB procedures, 3 were performed on an acute basis, 1 was performed on a semiacute basis, and the remaining 21 were elective. A novel 6 -point scoring system called the Leeds WEB aneurysm occlusion scale was created to ensure accurate assessment based on the morphology of the WEB device. Outcome was assessed at follow-up by MR angiography with or without digital subtraction angiography and the modified Rankin Scale (mRS).

RESULTS Deployment of the WEB device was successful in $22(88 \%)$ of 25 procedures; $3(12 \%)$ of the attempts at WEB treatment were abandoned. One of the patients in whom treatment was abandoned underwent a successful second attempt. Immediately after the 22 procedures with successful deployment, $4(18 \%)$ of the patients had a complete occlusion of the aneurysm and WEB device; 10 (45\%) had varying degrees of occlusion within the WEB device but no aneurysm neck or remnant; $3(14 \%)$ had a neck remnant; and $5(23 \%)$ had an aneurysm remnant. Of the patients with an aneurysm remnant, 1 had a complete aneurysm occlusion at $\geq 3$-months follow-up. In total, 6 (27\%) patients had a residual aneurysm at $\geq 3$-months radiological follow-up. One of these patients was admitted with hydrocephalus secondary to a recurrent aneurysm and later received a second WEB treatment with additional coiling. Only 1 patient developed new neurological symptoms. This patient went from an $\mathrm{mRS}$ score of 0 to a score of 1 and had radiological evidence of a thromboembolic event. Two patients showed radiological evidence of a new thromboembolic event on follow-up MRI but were clinically asymptomatic.

CONCLUSIONS The WEB has shown itself to be a promising new device with the potential to increase the scope of treatment for difficult wide-necked bifurcation aneurysms. The technique is safe, and short-term results show effective occlusion of complex aneurysms with minimal complications associated with the procedure. Long-term efficacy, however, still needs to be assessed.

http://thejns.org/doi/abs/10.3171/2015.4.JNS142456

KEY WORDS Woven EndoBridge; WEB; cerebral aneurysm; interventional neuroradiology; interventional neurosurgery; vascular disorders

\footnotetext{
ABBREVIATIONS $\mathrm{ACOA}=$ anterior communicating artery; $\mathrm{DSA}=$ digital subtraction angiography; ICA = internal carotid artery; ISAT = International Subarachnoid Aneurysm Trial; $M C A=$ middle cerebral artery; MRA = MR angiography; $\mathrm{mRS}=$ modified Rankin Scale; PCoA = posterior communicating artery; $\mathrm{SAH}=$ subarachnoid hemorrhage; WEB = Woven EndoBridge; WEB DL = WEB dual layer; WEB SL = WEB single layer; WEB SLS = WEB single-layer sphere.

SUBMITTED November 5, 2014. ACCEPTED April 7, 2015.

INCLUDE WHEN CITING Published online April 15, 2016; DOI: 10.3171/2015.4.JNS142456.
} 

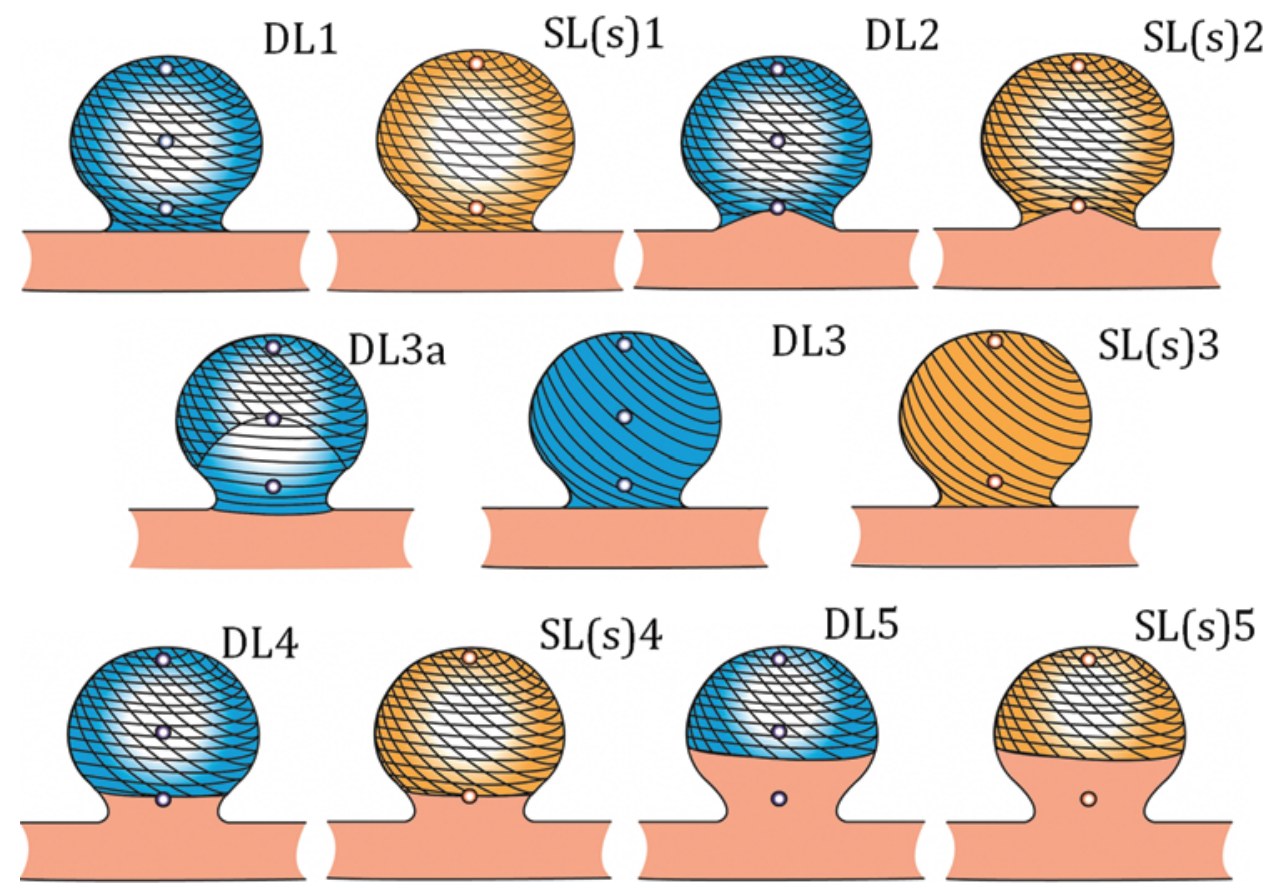

FIG. 1. Illustration of the Leeds WEB aneurysm occlusion scale. $\mathrm{DL}=$ double layer; $\mathrm{SL}(\mathrm{s})=$ single layer, where (s) indicates that the single-layer sphere device is included in this grade. Figure is available in color online only.

$\mathrm{T}$ HE treatment of cerebral aneurysms has seen many exciting developments and changes over the past 20 years. Since the first treatment experience with the Guglielmi detachable coils in $1991,6,7$ there has been an increasing shift in practice from surgical clipping to endovascular treatment in Western Europe. In 2002, the International Subarachnoid Aneurysm Trial (ISAT) secured the future of interventional coiling as the preferential treatment option for cerebral aneurysms. ${ }^{13}$ Since publication of the ISAT results, however, balloons/stents and flow diverters have been introduced as adjuncts in aneurysm treatment. ${ }^{18}$

The Woven EndoBridge (WEB) aneurysm embolization system (Sequent Medical) represents a new technique, which seeks to provide an alternative solitary treatment option to secure brain aneurysms. The WEB system is the first of its kind to provide a rival treatment option to clipping or coiling. The WEB is a self-expanding mesh that can be deployed from the microcatheter into a saccular aneurysm. After deployment, it remains retrievable and thereafter can be detached. It is particularly useful for treatment of wide-necked bifurcation aneurysms that would provide technical difficulties for coiling. The first cases of WEB embolization were published in 2011.,10 More recent publications have shown the benefit of using the WEB device in complex aneurysm treatment, but there is still a lack of data about the risk and benefits of the device and complications associated with treatment using the device.

In our center, the use of the WEB has been reserved for selected patients who have limited treatment options due to expected technical difficulty with conventional coil embolization and/or clipping and may require stent-assisted coiling. We present our initial series of selected complex aneurysms that were treated using the WEB device. Previous publications have used standard scales to assess the immediate and follow-up data in WEB treatment, but use of these scales is fraught with problems. ${ }^{4,11,19,20}$ We have designed a new 6-point scale with the specific morphology of the WEB device in mind. This scale, which we refer to as the Leeds WEB aneurysm occlusion scale, provides a comprehensive assessment, which includes consideration of the impact of the distal and proximal basket on aneurysm occlusion (Fig. 1). We provide a comparison with the much-used 3-point Raymond scale ${ }^{23}$ (Fig. 2). Both the Leeds and the Raymond scales were used immediately after the procedure and also to assess radiological outcome with either MR angiography (MRA) or digital subtraction angiography (DSA) at follow-up. The modified Rankin Scale (mRS; with 0 indicating no symptoms, 1 no significant disability, 2 slight disability, 3 moderate disability, 4 moderately severe disability, 5 severe disability, and 6 death) was chosen as the clinical follow-up outcome measure, as it is a recognized outcome scale for neurological patients. ${ }^{1}$ We would like to present our experience with a specific emphasis on the immediate postembolization results, complication rates, and short-term follow-up results in our series of patients treated with WEB. In particular, we would like to present the difficulties associated with using standard scales to assess the radiological outcome of WEB aneurysm treatment and the advantages of using our new scale to assess the radiological outcome for this purpose.

It should be noted that the WEB devices are not currently available for sale or use in the United States. 
A: Raymond Class 1 Complete Obliteration
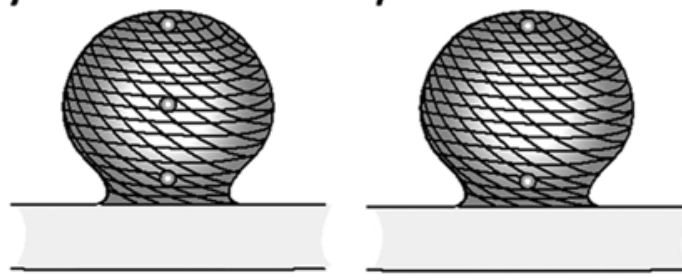

B: Raymond Class 2 Residual Neck
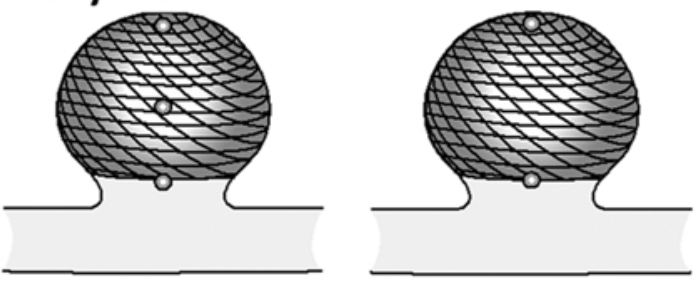

C: Raymond Class 3 Residual Aneurysm
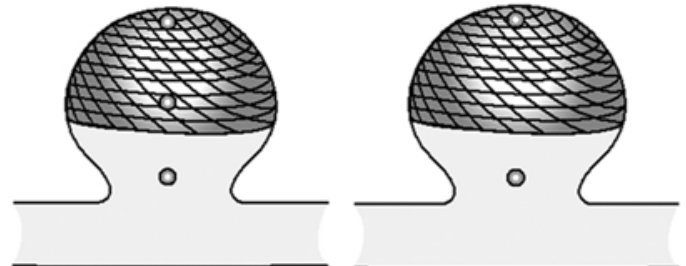

FIG. 2. Illustration of Raymond scale classification. A: Class 1, complete obliteration. B: Class 2, residual neck. C: Class 3, residual aneurysm. Based on Roy et al. ${ }^{23}$

\section{Methods}

Twenty-five WEB procedures were performed between April 2013 and April 2014 in 23 patients. The patients in this case series had aneurysms that were challenging to treat and in many cases limited options. The decision making for these patients was held in a neurovascular multidisciplinary team meeting where the benefits and disadvantages of all treatment options were carefully considered by neurosurgical and neuroradiology consultants. All data were collected prospectively, anonymized, and stored within a password-protected database.

A wealth of information was recorded for each patient including age, sex, presentation, ISAT aneurysm location, morphology, indication (reason for WEB device choice), and aneurysm size. The widest part of the aneurysm was used for measurements. Aneurysm height, neck diameter, and sac width were measured in an anteroposterior projection, and depth was measured in a lateral projection. The aspect ratio was calculated using aneurysm height divided by the neck diameter. All complications were carefully documented. Posttreatment imaging assessment included the immediate postprocedure angiogram, MRI and MRA at follow-up ( $\geq 3$ months), and at angiographic follow-up (depending on clinical need). The degree of aneurysm occlusion was rated using our Leeds WEB aneurysm occlusion scale and the Raymond scale (Table 1, Figs. 1-4).

Clinical follow-up included a 6-week review in the neurovascular clinic and an additional appointment or tele-
TABLE 1. Leeds WEB aneurysm occlusion scale

\begin{tabular}{ll}
\hline \multicolumn{1}{c}{ Score } & \multicolumn{1}{c}{ Description } \\
\hline $\mathrm{DL} / \mathrm{SL}(\mathrm{s}) 1$ & Complete occlusion \\
\hline $\mathrm{DL} / \mathrm{SL}(\mathrm{s}) 2$ & Complete occlusion w/ proximal recess \\
\hline $\mathrm{DL} \mathrm{3a}$ & $\begin{array}{c}\text { Proximal basket opacification w/ complete occlusion of } \\
\text { the distal basket }\end{array}$ \\
\hline $\mathrm{DL} / \mathrm{SL}(\mathrm{s}) 3$ & Slow filling of the WEB device $\mathrm{w} /$ stasis \\
\hline $\mathrm{DL} / \mathrm{SL}(\mathrm{s}) 4$ & Neck remnant \\
\hline $\mathrm{DL} / \mathrm{SL}(\mathrm{s}) 5$ & Aneurysm remnant \\
\hline
\end{tabular}

$\mathrm{DL}=$ double layer; $\mathrm{SL}(\mathrm{s})$ = single layer, where $(\mathrm{s})$ indicates that the single-layer sphere device is included in this grade. See Fig. 1 for an illustration of the scale.

phone call at a minimum of 3 months after the procedure (depending on the patient's clinical need) by a neurosurgical registrar. The $\mathrm{mRS}^{22,24}$ was used before treatment and at the latest clinical follow-up in order to assess clinical outcome.

\section{Device and Procedure}

All 3 varieties of the WEB device were employed in this series. The WEB device is a flow disruptor made from fine Nitinol wires of mixed diameters that together form a dense compliant mesh. The WEB dual layer (DL) device was the first WEB device to be used to treat brain aneurysms. The WEB DL has an outer mesh and an internal mesh that sits within the proximal portion of the outer mesh. It has 3 radiopaque markers. The markers lie centrally at the top of the outer mesh and inner mesh. The third marker lies at the most proximal central part of the WEB. This area is concave to prevent thrombus formation. The WEB single-layer (SL) device was introduced more recently. This device does not have the internal layer of mesh but is still sized by width and height. The newest edition to the family is the WEB single-layer sphere (SLS). The WEB SLS has the same height as width and is available in larger diameters than the WEB SL. Both the SL and SLS have only 2 radiolucent markers, which lie centrally at the most distal and proximal ends. The DL, SL, and SLS all have a proximal recess due to the concave shape of the base. The WEB utilizes electrothermal detachment technology using a handheld controller.

The technique has been previously described. ${ }^{12,19}$ An 8-Fr NeuroMax guide sheath is navigated in the main artery (vertebral or internal carotid artery). The distal access catheter used in our series was the Navien (Covidien), FargoMax (Balt), or Neuron catheter (Penumbra) for stability. Different specific microcatheters can be used for the different sizes of WEB devices. Popular choices were the DAC (Stryker) and the VIA and VIA Plus microcatheters (Sequent Medical). The SL and SLS devices have a lower profile and were designed for use with the VIA-27 and VIA-33 catheters (Sequent Medical) that are 3 Fr and 3.4 Fr (outer diameter), respectively. The VIA-33 is dedicated to the WEB SL and SLS devices with diameters of $10 \mathrm{~mm}$ and above. No specific guidewire is favored at our institution, and the choice was at the operator's discretion. Guidewires selected included the Synchro14 (Boston Scientific), 

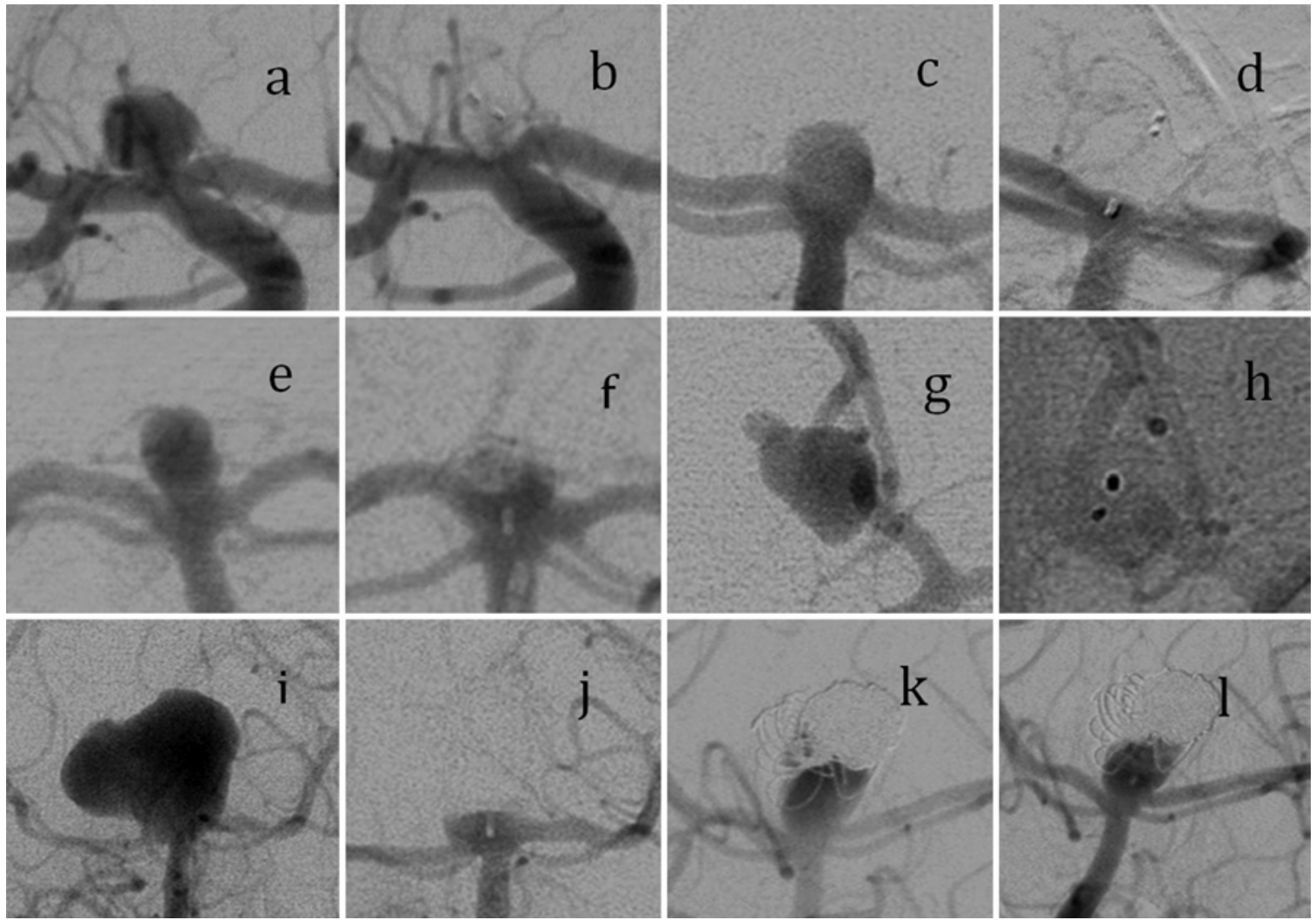

FIG. 3. Angiographic images depicting the Leeds WEB aneurysm scale applied to treatment with a double-layer device. a and b: Pretreatment (a) and posttreatment (b) images obtained in Case 8 (right ICA aneurysm). The posttreatment angiogram shows a DL1 result. c and d: Pretreatment (c) and posttreatment (d) images obtained in Case 17 (basilar tip aneurysm). The posttreatment image shows a DL2 result. e and f: Pretreatment (e) and posttreatment (f) images in Case 14 (basilar tip aneurysm). The posttreatment image shows a DL3a result. $\mathrm{g}$ and $\mathrm{h}$ : Pretreatment $(\mathrm{g})$ and posttreatment $(\mathrm{h})$ images obtained in Case 22 (ACoA aneurysm). The posttreatment image shows a DL3 result. i and j: Pretreatment (i) and posttreatment (j) images obtained in Case 9 (basilar tip aneurysm). The posttreatment image shows a DL4 result. $\mathbf{k}$ and I: Pretreatment (k) and posttreatment (I) images obtained in Case 7 (basilar tip aneurysm). The posttreatment image shows a DL5 result.

Asahi 14 (Asahi Intecc), and Terumo 16 (Terumo Medical Corporation). During the procedure all patients received a standard dose of 5000 units of heparin, administered intravenously. Additional heparin was administered (intravenously) if needed to keep the activated clotting time between 1.5 and 2 times the patient's baseline. Additional anticoagulation (e.g., intravenously administered aspirin, pre-/postprocedure anticoagulation) was case dependent (e.g., concern regarding thrombus intraprocedure).

\section{Population}

The study population included 22 patients who underwent a total of 25 procedures. In 2 patients, the first WEB procedure failed, and the patients underwent a second (successful) WEB procedure. One patient had a successful insertion of a WEB device but subsequently experienced aneurysm recurrence and returned for insertion of a second WEB device. Thus there were a total of 23 successful procedures. Of the 25 procedures performed, 12 were for the treatment of incidental aneurysms, 9 were for symptomatic aneurysms, 1 for a recurrent aneurysm, and 3 for treatment of lesions in patients who presented with an acute subarachnoid hemorrhage (SAH). There were 3 acute cases ( $\mathrm{SAH}$ ) and 1 semiacute case; the patient in the semiacute case had developed hydrocephalus secondary to a recurrent basilar aneurysm. Eleven patients had basilar tip aneurysms, which was the most common aneurysm treated within this cohort. All the aneurysms were saccular, and 4 were partially thrombosed. Of the 25 procedures, 21 involved aneurysms with a neck greater than 4 $\mathrm{mm}$ in diameter. Four aneurysms had necks under $4 \mathrm{~mm}$ in diameter, but of these, only 1 aneurysm had an aspect ratio over 2 (see Table 2). This aneurysm (a posterior communicating artery [PCoA] lesion) had been ruptured by a Synchro wire during attempted catheterization, and the WEB device was used in a rescue procedure to control the hemorrhage.

\section{Results}

From April 2013 until April 2014, the WEB procedure was undertaken in 25 cases (involving 23 successful insertions of the WEB device in 22 patients). The mean age of the patients at the time of the procedure was 57.3 years. Seven of the patients were male, and 18 were female. There were no giant aneurysms $(>25 \mathrm{~mm})$ in this series. The smallest aneurysm was $3 \times 4 \times 4 \mathrm{~mm}$. The largest 

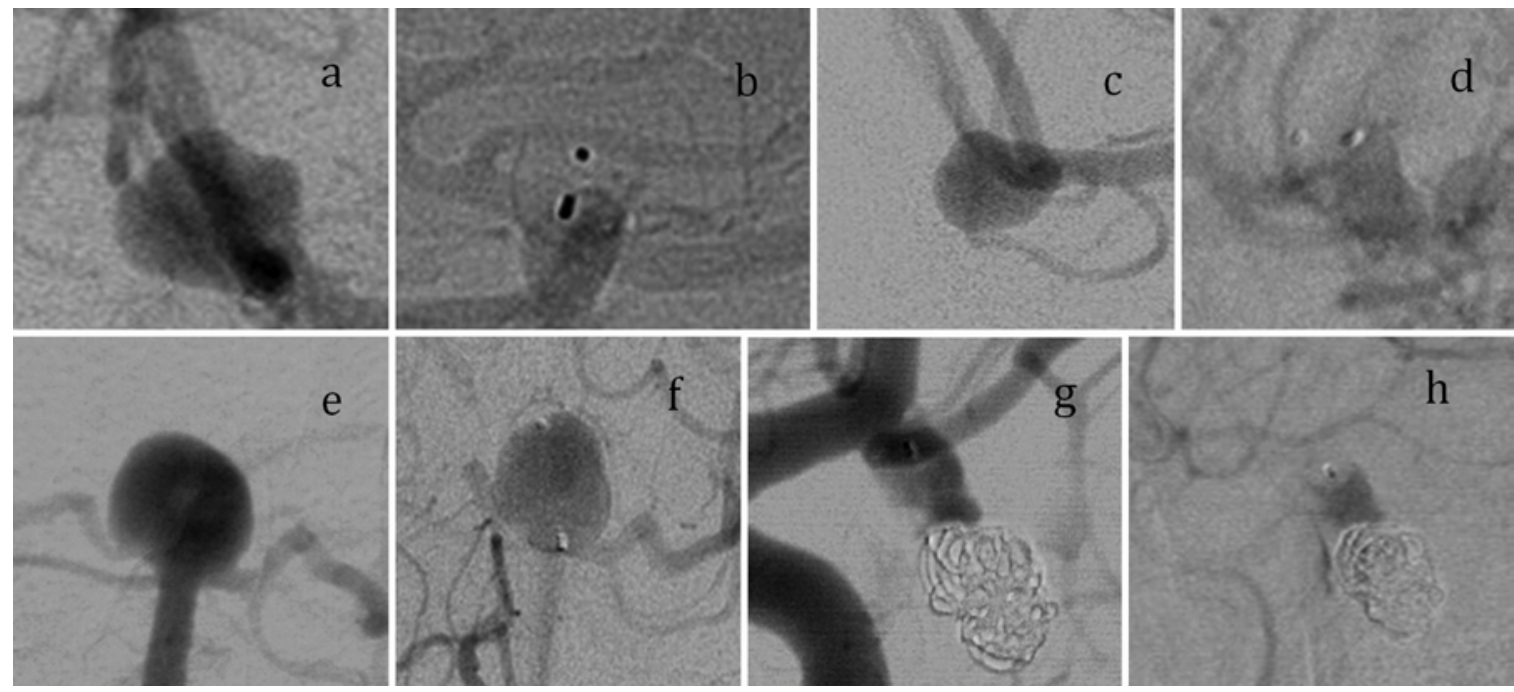

FIG. 4. Angiographic images depicting the Leeds WEB aneurysm scale applied to treatment with a single-layer device. a and $b$ : Pretreatment (a) and posttreatment (b) images obtained in Case 12 (right MCA aneurysm). The posttreatment angiogram shows an $\mathrm{SL}(\mathrm{s}) 1$ result. c and d: Pretreatment (c) and posttreatment (d) images obtained in Case 23 (right MCA aneurysm). The posttreatment angiogram shows an SL(s)2 result. e and f: Pretreatment (e) and posttreatment (f) images obtained in Case 18 (basilar tip aneurysm). The posttreatment image shows an SL(s)3 result. $g$ and $h$ : Pretreatment (g) and posttreatment (h) images obtained in Case 24 (right PCoA aneurysm). The posttreatment angiogram shows an SL(s)4 result. (There was no case available to demonstrate SL[s]5).

aneurysm was $15 \times 13 \times 10 \mathrm{~mm}$. From this series of cases, 11 involved basilar tip aneurysms, 5 involved middle cerebral artery (MCA) aneurysms, 3 involved internal carotid artery (ICA) aneurysms, 3 involved anterior communicating artery $(\mathrm{ACoA})$ aneurysms, and 3 involved PCoA aneurysms. Two patients had aneurysms that were partially thrombosed. The indication for the WEB procedure was recorded. From this group of 25 procedures, 24 were for wide-necked $(>4 \mathrm{~mm})$ aneurysms and 19 were for bifurcation aneurysms. Eight procedures were performed because there was no neurosurgical option, and 2 were performed after previous failed procedures.

Of this group of 25 procedures, three (Cases 2, 16, and 19) were abandoned due to access difficulties. The patients in these cases were treated with coiling in 2 instances, and in the third instance (Case 16), a second WEB procedure was scheduled and successfully completed (Case 21). One patient had a recurrence of the aneurysm and underwent placement of a second WEB device along with coils 6 months after the first treatment (Cases 4 and 25). The patient in Case 6 had a flow diverter Pipeline device (Covidien) placed across the neck of the aneurysm because the WEB device was not positioned well and there was persistent flow.

\section{Immediate Angiographic Results and Radiographic Follow-Up}

The mean immediate postprocedure Leeds score (based on MRA or DSA) was 3.1 (range of 1-5, median 3). The mean value at the most recent follow-up evaluation (at a minimum of 3 months after the procedures) was 2.9 (range 1-5, median 3). Four patients (18\%) had complete occlusion of their aneurysm (Leeds Score 1, Raymond Class 1) immediately after the procedure. Three of these aneurysms remained occluded (Table 3). One aneurysm was found to have recurred (Leeds Score 5, Raymond Class 2) at the 9-month angiographic follow-up and is currently under surveillance. Two patients had flow within the proximal recess after the procedure (Leeds Score 2, Raymond Class 2). This remained stable in 1 patient. In the other patient there was evidence of some proximal basket opacification (incomplete proximal basket occlusion, Leeds Score 3a/Raymond Class 3) at follow-up. Two patients (9\%) had an incomplete proximal basket occlusion (Leeds Score 3a/Raymond Class 3) immediately postprocedure. One of these patients had a recurrence of the aneurysm at follow-up (Case 4), and this patient has recently undergone a second WEB treatment and adjunct coiling. The other patient has remained stable with no change. Six patients $(27 \%)$ were noted to have slow flow (Leeds Score 3, Raymond Class 3) throughout the WEB device in the immediate postprocedure studies. This is an interesting group, as immediate angiographic results of slow flow are interpreted with the understanding that further thrombosis and occlusion of aneurysm is likely to occur. Indeed at follow-up all of these patients demonstrated an improved occlusion appearance. In 4 cases complete occlusion (Leeds Score 1, Raymond Class 1) was achieved. In 1 case the proximal recess was still visible (Leeds Score 2, Raymond Class), and in 1 other case part of the proximal basket of the device was seen (Leeds Score 3a, Raymond Class 3). In 3 cases $(14 \%)$ there was a neck remnant (Leeds Score 4/Raymond Class 2), and in all 3 of these cases, the lesion remained stable at follow-up. In 5 cases an aneurysm remnant was evident on immediate postprocedure imaging (Leeds Score 5/Raymond Class 3). This remained stable in 4 cases. In 1 case the aneurysm became completely occluded (Leeds Score 1, Raymond Class 1) at follow-up 
TABLE 2. Patient demographic characteristics, presentation, nature of aneurysm, and indication for WEB

\begin{tabular}{|c|c|c|c|c|c|c|c|c|c|c|}
\hline $\begin{array}{l}\text { Case } \\
\text { No. }\end{array}$ & Age & Sex & Presentation & $\begin{array}{l}\text { Acute/ } \\
\text { Elective }\end{array}$ & $\begin{array}{l}\text { ISAT Aneurysm } \\
\text { Location }\end{array}$ & Indication & $\begin{array}{c}\text { Aneurysm Size }(\mathrm{mm}), \\
\text { AP View }\end{array}$ & $\begin{array}{c}\text { Aspect Ratio } \\
\text { (height/neck } \\
\text { diam) }\end{array}$ & $\begin{array}{l}\text { WEB } \\
\text { Size } \\
(\mathrm{mm})\end{array}$ & $\mathrm{SL}$ or $\mathrm{DL}$ \\
\hline 1 & 51 & M & Symptomatic & Elective & $\begin{array}{l}\text { Midline basilar tip } \\
\text { (thrombosed) }\end{array}$ & $\begin{array}{l}\text { Wide, bifurc, no NS } \\
\text { option }\end{array}$ & $\begin{array}{l}H: 12.56 ; W: 9.9 ; \\
\quad \text { N: } 5.05 ; D: 13.04\end{array}$ & 2.49 & $11 \times 9$ & $\mathrm{DL}$ \\
\hline 2 & 62 & $F$ & Symptomatic & Elective & Midline basilar tip & $\begin{array}{l}\text { Wide, bifurc, no NS } \\
\text { option }\end{array}$ & $\begin{array}{c}\mathrm{H}: 11.34 ; \mathrm{W}: 10.24 \\
\mathrm{~N}: 8.53 ; \mathrm{D}: 9.72\end{array}$ & 1.33 & NA & NA \\
\hline 3 & 53 & $\mathrm{~F}$ & Incidental & Elective & Lt MCA & Wide, bifurc, failure & $\begin{array}{l}\mathrm{H}: 4.35 ; \mathrm{W}: 5.10 \\
\mathrm{~N}: 4.08 ; \mathrm{D}: 7.33\end{array}$ & 1.07 & $6 \times 3$ & $\mathrm{DL}$ \\
\hline 4 & 61 & M & Symptomatic & Elective & $\begin{array}{l}\text { Midline basilar tip } \\
\text { (thrombosed) }\end{array}$ & Wide, bifurc & $\begin{array}{l}\mathrm{H}: 14.34 ; \mathrm{W}: 11.17 \\
\quad \mathrm{~N}: 8.87 ; \mathrm{D}: 14.08\end{array}$ & 1.62 & $11 \times 9$ & $\mathrm{DL}$ \\
\hline 5 & 47 & $M$ & $\mathrm{SAH}$ & Acute & Midline basilar tip & $\begin{array}{l}\text { Wide, bifurc, no NS } \\
\text { option }\end{array}$ & $\begin{array}{l}\mathrm{H}: 5.47 ; \mathrm{W}: 7.94 ; \mathrm{N}: 7.91 \\
\quad \text { D: } 6.39\end{array}$ & 0.69 & $8 \times 4$ & $\mathrm{DL}$ \\
\hline 6 & 54 & $\mathrm{~F}$ & Symptomatic & Elective & Rt ICA & Wide, no NS option & $\begin{array}{l}\mathrm{H}: 8.9 ; \mathrm{W}: 14.5 ; \mathrm{N}: 8.9 ; \\
\quad \mathrm{D}: 14.7\end{array}$ & 1.00 & $11 \times 7$ & $\mathrm{DL}$ \\
\hline 7 & 69 & $M$ & Symptomatic & Elective & Midline basilar tip & Wide, bifurc & $\begin{array}{l}\mathrm{H}: 5.00 ; \mathrm{W}: 7.00 ; \mathrm{N}: 6.8 \\
\text { D: } 7.33\end{array}$ & 0.77 & $8 \times 4$ & $\mathrm{DL}$ \\
\hline 8 & 33 & M & Symptomatic & Elective & Rt ICA & Wide, bifurc & $\begin{array}{l}\mathrm{H}: 5.52 ; \mathrm{W}: 7.74 ; \mathrm{N}: 5.00 ; \\
\quad \text { D: } 6.26\end{array}$ & 0.77 & $7 \times 4$ & $\mathrm{DL}$ \\
\hline 9 & 63 & $\mathrm{~F}$ & Incidental & Elective & Midline basilar tip & Wide, bifurc & $\begin{array}{l}\mathrm{H}: 15.43 ; \mathrm{W}: 16.00 \\
\quad \mathrm{~N}: 8.6 ; \mathrm{D}: 9.72\end{array}$ & 1.10 & $10 \times 8$ & $\mathrm{DL}$ \\
\hline 10 & 60 & $\mathrm{~F}$ & Incidental & Elective & Rt ACoA & $\begin{array}{l}\text { Wide, bifurc, no NS } \\
\text { option }\end{array}$ & $\begin{array}{l}\mathrm{H}: 6.00 ; \mathrm{W}: 7.92 ; \mathrm{N}: 7.29 \\
\quad \text { D: } 11.05\end{array}$ & 0.82 & $9 \times 5$ & $\mathrm{DL}$ \\
\hline 11 & 56 & M & Symptomatic & Elective & ACoA (thrombosed) & Wide & $\begin{array}{l}\mathrm{H}: 9.50 ; \mathrm{W}: 6.39 \\
\mathrm{~N}: 6.94 ; \mathrm{D}: 7.30\end{array}$ & 1.37 & $9 \times 6$ & $\mathrm{DL}$ \\
\hline 12 & 49 & $\mathrm{~F}$ & Incidental & Elective & Rt MCA proximal & Wide, bifurc & $\begin{array}{l}\mathrm{H}: 7.06 ; \mathrm{W}: 5.50 ; \mathrm{N}: 5.12 ; \\
\quad \mathrm{D}: 6.42\end{array}$ & 1.38 & $7 \times 5$ & SL \\
\hline 13 & 55 & $\mathrm{~F}$ & Incidental & Elective & Lt PCoA & Acute rupture & $\begin{array}{l}H: 5.66 ; W: 5.25 \\
\quad \text { N: } 2.50 ; D: 5.06\end{array}$ & 2.26 & 6 & SLS \\
\hline 14 & 59 & $\mathrm{~F}$ & Incidental & Elective & Midline basilar tip & Wide, bifurc & $\begin{array}{l}\mathrm{H}: 4.36 ; \mathrm{W}: 4.2 ; \mathrm{N}: 3.10 ; \\
\quad \text { D: } 3.93\end{array}$ & 1.41 & $5 \times 3$ & $\mathrm{DL}$ \\
\hline 15 & 43 & $\mathrm{~F}$ & $\begin{array}{r}\text { Recurrent/ } \\
\text { residual }\end{array}$ & Elective & Midline basilar tip & $\begin{array}{l}\text { Wide, bifurc, no NS } \\
\text { option }\end{array}$ & $\begin{array}{l}\mathrm{H}: 4.71 ; \mathrm{W}: 5.43 ; \mathrm{N}: 5.42 \\
\quad \text { D: } 5.16\end{array}$ & 0.87 & $6 \times 3$ & $\mathrm{DL}$ \\
\hline 16 & 47 & $\mathrm{~F}$ & Incidental & Elective & Lt MCA & Wide & $\begin{array}{l}H: 3.44 ; \text { W: } 3.82 \\
\quad \text { N: } 2.35 ; D: 4.06\end{array}$ & 1.46 & NA & NA \\
\hline 17 & 49 & $\mathrm{~F}$ & Incidental & Elective & Midline basilar tip & $\begin{array}{l}\text { Wide, bifurc, no NS } \\
\text { option }\end{array}$ & $\begin{array}{l}H: 7.46 ; W: 6.44 ; \\
\quad \text { N: } 5.50 ; D: 8.04\end{array}$ & 1.36 & $8 \times 5$ & $\mathrm{DL}$ \\
\hline 18 & 71 & $\mathrm{~F}$ & $\mathrm{SAH}$ & Acute & Basilar tip & $\begin{array}{l}\text { Wide, bifurc, no NS } \\
\text { option }\end{array}$ & $\begin{array}{l}H: 9.2 ; W: 10.55 \\
\quad \text { N: } 8.98 ; D: 9.50\end{array}$ & 1.02 & 10 & SLS \\
\hline 19 & 70 & $\mathrm{~F}$ & Incidental & Elective & Lt terminal ICA & Wide, bifurc & $\begin{array}{l}\mathrm{H}: 3.32 ; \mathrm{W}: 5.95 \\
\quad \mathrm{~N}: 4.20 ; \mathrm{D}: 5.53\end{array}$ & 0.79 & NA & NA \\
\hline 20 & 70 & $\mathrm{~F}$ & Incidental & Elective & Lt PCoA & Wide & $\begin{array}{l}\mathrm{H}: 7.53 ; \mathrm{W}: 6.79 ; \mathrm{N}: 6.24 \\
\quad \text { D: } 7.86\end{array}$ & 1.21 & 8 & SLS \\
\hline 21 & 47 & $\mathrm{~F}$ & Incidental & Elective & Lt MCA & Wide & $\begin{array}{l}\mathrm{H}: 3.44 ; \mathrm{W}: 3.82 \\
\quad \mathrm{~N}: 2.35 ; \mathrm{D}: 4.06\end{array}$ & 1.46 & 4 & SLS \\
\hline 22 & 53 & $\mathrm{~F}$ & $\mathrm{SAH}$ & Acute & $\mathrm{ACoA}$ & Wide, bifurc & $\begin{array}{l}\mathrm{H}: 7.63 ; \mathrm{W}: 8.09 ; \\
\quad \text { N: 5.30; D: 7.56; }\end{array}$ & 1.44 & $9 \times 6$ & $\mathrm{DL}$ \\
\hline 23 & 67 & $\mathrm{~F}$ & Incidental & Elective & Rt MCA & Wide, bifurc & $\begin{array}{l}\mathrm{H}: 6.67 ; \mathrm{W}: 6.54 ; \\
\quad \mathrm{N}: 4.50 ; \mathrm{D}: 6.17\end{array}$ & 1.48 & $7 \times 5$ & $S L$ \\
\hline 24 & 83 & $\mathrm{~F}$ & Symptomatic & Elective & Rt PCoA & Wide, bifurc & $\begin{array}{l}\mathrm{H}: 15.55 ; \mathrm{W}: 7.21 ; \\
\quad \mathrm{N}: 4.57 ; \mathrm{D}: 7.38\end{array}$ & 4.06 & $6 \times 4$ & SL \\
\hline 25 & 61 & $M$ & Symptomatic & Semiacute & $\begin{array}{l}\text { Midline basilar tip } \\
\text { (thrombosed) }\end{array}$ & Wide, bifurc, failure & $\begin{array}{l}\mathrm{H}: 15.02 ; \mathrm{W}: 12.70 ; \\
\quad \mathrm{N}: 11.42 ; \mathrm{D}: 10.19\end{array}$ & 1.32 & $11 \times 9$ & SL \\
\hline
\end{tabular}

$\mathrm{AP}=$ anteroposterior; bifurc $=$ bifurcation; $\mathrm{D}=$ depth; diam = diameter; failure $=$ failure of previous procedure; $\mathrm{H}=$ height; $\mathrm{NA}=$ not applicable; $\mathrm{N}=$ neck diameter; $\mathrm{NS}=$ neurosurgical; $\mathrm{W}=$ width; wide $=$ wide necked $(>4 \mathrm{~mm}$ neck diameter) . 
TABLE 3. Radiographic results

\begin{tabular}{|c|c|c|c|c|c|c|c|}
\hline \multirow{2}{*}{$\begin{array}{c}\text { Case } \\
\text { No. }\end{array}$} & \multirow[b]{2}{*}{ Aneurysm } & \multicolumn{2}{|c|}{ Immediately After Procedure } & \multicolumn{2}{|c|}{ FU MRI/MRA } & \multicolumn{2}{|c|}{ FU Angiography } \\
\hline & & Leeds Scale & Raymond Scale & Leeds Scale & Raymond Scale & Leeds Scale & Raymond Scale \\
\hline 1 & $\begin{array}{l}\text { Midline basilar tip } \\
\text { (thrombosed) }\end{array}$ & 5 & 3 & 5 (1 mo); 5 (13 mos) & 3 (1 mo); 3 (13 mos) & 5 (6 mos) & 3 (6 mos) \\
\hline 2 & Midline basilar tip & - & - & - & - & - & - \\
\hline 3 & Lt MCA & 1 & 1 & 1 (6 mos) & 1 (6 mos) & 5 (9 mos) & 3 \\
\hline 4 & $\begin{array}{l}\text { Midline basilar tip } \\
\text { (thrombosed) }\end{array}$ & $3 a$ & 3 & 3a (3 mos); 5 (9 mos) & 3 (3 mos); 3 (9 mos) & 5 (9 mos) & 3 \\
\hline 5 & Midline basilar tip & 3 & 3 & $3 a(6$ mos $)$ & 3 (6 mos) & NA & NA \\
\hline 6 & Rt ICA & 5 & 3 & NA & NA & 1 (8 mos) & 1 \\
\hline 7 & Midline basilar tip & 5 & 3 & 5 (2 wks); 5 (6 mos) & 3 (2 wks); 3 (6 mos) & NA & NA \\
\hline 8 & Rt ICA & 1 & 1 & 1 (6 wks); DNA FU & 1 (6 wks); DNA FU & NA & NA \\
\hline 9 & Midline basilar tip & 4 & 2 & 4 (3 mos); 4 (8 mos) & 2 (3 mos); 2 (8 mos) & NA & NA \\
\hline 10 & Rt ACoA & 5 & 3 & 5 (3 mos) & $3(3 \mathrm{mos})$ & 5 (8 mos) & \\
\hline 11 & ACoA (thrombosed) & 5 & 3 & 5 (3 mos); 5 (10 mos) & 3 (3 mos); 3 (10 mos) & NA & NA \\
\hline 12 & Rt MCA proximal & 1 & 1 & 1 (7 mos) & 1 (7 mos) & NA & NA \\
\hline 13 & Lt PCoA & 1 & 1 & 1 (6 mos) & 1 (6 mos) & NA & NA \\
\hline 14 & Midline basilar tip & 3 & 3 & MRA: 1 (3 mos) & 1 (3 mos) & NA & NA \\
\hline 15 & Midline basilar tip & 3 & 3 & 2 (6 mos) & 2 (6 mos) & NA & NA \\
\hline 16 & Lt MCA & - & - & - & - & - & - \\
\hline 17 & Midline basilar tip & 2 & 2 & 3a (1 mo); 3a (6 mos) & 3 (1 mo); 3 (6 mos) & NA & NA \\
\hline 18 & Basilar tip & 3 & 3 & 1 (6 mos) & 1 (6 mos) & NA & NA \\
\hline 19 & Lt terminal ICA & - & - & - & - & - & - \\
\hline 20 & Lt PCoA & 3 & 3 & 1 (3 mos) & 1 (3 mos) & NA & NA \\
\hline 21 & Lt MCA & 3 & 3 & 1 (3 mos) & 1 (3 mos) & NA & NA \\
\hline 22 & $\mathrm{ACoA}$ & $3 a$ & 3 & $3 a(3 \mathrm{mos})$ & 3 (3 mos) & NA & NA \\
\hline 23 & Rt MCA & 2 & 2 & 2 (3 mos) & 2 (3 mos) & NA & NA \\
\hline 24 & Rt PCoA & 4 & 2 & 4 (3 mos) & 2 (3 mos) & NA & NA \\
\hline 25 & $\begin{array}{l}\text { Midline basilar tip } \\
\text { (thrombosed) }\end{array}$ & 4 & 2 & 4 (2 wks) & 2 (2 wks) & NA & NA \\
\hline
\end{tabular}

DNA = did not attend; FU = follow-up; $-=$ unsuccessful WEB insertion.

(Table 3). A summary chart and table have been constructed with the results of immediate and follow-up imaging with respect to aneurysm occlusion (Fig. 5, Table 4).

\section{Complications}

Three patients had new areas of radiographic infarction seen on follow-up imaging (Table 3). All three of these patients had a residual aneurysm or neck remnant immediately postprocedure. The patient in Case 7 had a 2-week MRA that revealed a new area of asymptomatic infarct indicating a thromboembolic event. This was likely to have occurred at the time of the procedure. The patient in Case 9 had a 3-month MRA study that showed radiographic evidence of bilateral small occipital infarcts. The patient was asymptomatic immediately after the procedure and at follow-up. The patient in Case 11 had evidence of infarct with new neurological deficit that occurred immediately postprocedure. In retrospect, the WEB device used for this patient was considered oversized, highlighting the importance of accurate sizing of the device.

The patient in Case 13 had an aneurysm rupture dur- ing the procedure. This was not, however, a complication of the WEB device, as coil embolization was initially planned for the treatment of acute SAH. The aneurysm ruptured during the coil placement, and the WEB device was used as a rescue device for rapid aneurysm occlusion. The patient in Case 4 had a recurrent basilar tip aneurysm resulting in hydrocephalus and underwent a second WEB treatment (Case 25) with adjunctive coiling.

\section{Clinical Follow-Up}

Patients were assessed using the mRS. Of the 25 procedures, 3 were abandoned (Table 5). For the remaining 22 procedures, the mean preprocedure $\mathrm{mRS}$ score was 1.4 (range $0-5$, median 1). The mean mRS for clinical followup was 1 (range $0-4$, median 0.5). After 15 of these 22 procedures, the patients had no new symptoms either immediately after the WEB insertion or at follow-up. As a result, their mRS scores remained the same ( 0 in 8 cases, 1 in 4 cases, 3 in 2 cases, and 4 in 1 case). In 5 of these cases, the patients had an improvement in clinical symptoms (the mRS score went from 1 to 0 in 2 cases, from 5 


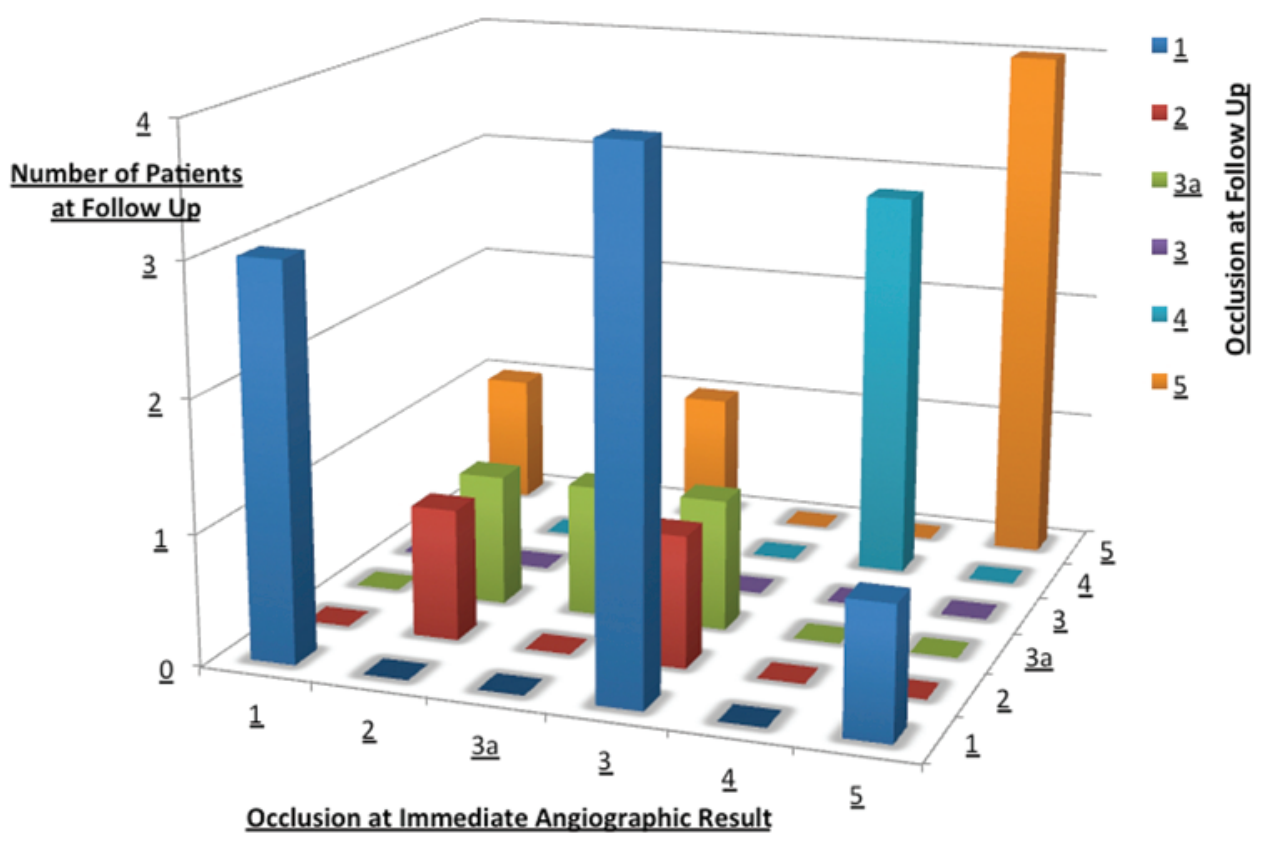

FIG. 5. Bar chart showing the number of patients with each Leeds WEB occlusion score (y-axis) at immediate post-WEB angiographic follow-up (x-axis) and the score at the latest MRA/DSA follow-up (z-axis). Figure is available in color online only.

to 0 in 1 case, from 5 to 1 in 1 case, and from 4 to 3 in 1 case). In 2 cases, the patients developed new symptoms after the WEB procedure. The patient in Case 11 developed a new facial palsy immediately after the procedure

TABLE 4. Summary of Leeds WEB aneurysm occlusion scale scores after the WEB treatment

\begin{tabular}{rrl}
\hline Case No. & Immediate Angiographic Result & $\begin{array}{c}\text { Result at Latest FU } \\
\text { (MRA/DSA) }\end{array}$ \\
\hline 3 & 1 & 5 (recurrence) \\
8 & 1 & 1 (NA as $<3$ mos) \\
12 & 1 & 1 \\
13 & 1 & 1 \\
\hline 23 & 2 & 2 \\
17 & 2 & $3 a$ \\
4 & $3 a$ & 5 (recurrence) \\
22 & $3 a$ & $3 a$ \\
\hline 5 & 3 & $3 a$ \\
14 & 3 & 1 \\
15 & 3 & 2 \\
18 & 3 & 1 \\
20 & 3 & 1 \\
21 & 3 & 1 \\
9 & 4 & 4 \\
24 & 4 & 4 \\
25 & 4 & 4 (NA as $<3$ mos) \\
\hline 1 & 5 & 5 \\
6 & 5 & 1 \\
7 & 5 & 5 \\
10 & 5 & 5 \\
11 & 5 & 5 \\
\hline
\end{tabular}

with radiographic evidence of ischemia. The deficit slowly improved, but there was still evidence of this neurological deficit at the 3-month follow-up evaluation (mRS score of 1). The patient in Case 4 (mRS score of 1 preprocedure) had a recurrence of a large basilar tip aneurysm at followup, which led to a readmission. The patient had developed hydrocephalus and underwent shunt insertion. The patient then had further treatment of the aneurysm with a second WEB device and adjunct coiling. This patient was not a candidate for stent diversion due to excess alcohol intake making anticoagulation therapy inappropriate. After the second treatment (Case 25) was an improvement in mRS score was seen at follow-up (from 4 to 3 ).

\section{Discussion}

In this paper, the patients selected for WEB treatment all had complex aneurysms that would prove difficult to treat with conventional coiling. Most of the patients had wide-neck and/or bifurcation aneurysms that would likely have required stent assistance. The probability of recurrence is reduced with stent-assisted coiling ${ }^{9}$ compared with standard coiling or balloon remodeling. ${ }^{3}$ The disadvantage of stent-assisted coiling is that the patient needs lifelong anticoagulation therapy. In addition, the complexities of this procedure increase the risk of complications. As the placement of the WEB mesh is within the aneurysm itself, long-term anticoagulation therapy is not needed; moreover, the procedural time is remarkably reduced, and the procedure is less complex.

The first publication on the WEB device (Type 1-single layer) was an animal trial (published in 2010) showing complete or near-complete occlusion of the aneurysm in $87 \%$ of cases. Histological examination showed fibers of connective tissue across the aneurysm neck and thrombus 
TABLE 5. Clinical results for WEB-treated patients

\begin{tabular}{|c|c|c|c|c|c|}
\hline \multirow[b]{2}{*}{ Case No. } & \multirow[b]{2}{*}{ Aneurysm } & \multirow[b]{2}{*}{ Complication } & \multicolumn{2}{|c|}{ MRS } & \multirow[b]{2}{*}{ New Sx } \\
\hline & & & Preprocedure & FU & \\
\hline 1 & Midline basilar tip (thrombosed) & None & 1 & 0 (6 mos) & No \\
\hline 2 & Midline basilar tip & Abandoned (stent-assisted coiling) & - & - & - \\
\hline 3 & Lt MCA & None & 1 & 1 (9 mos) & No \\
\hline 4 & Midline basilar tip (thrombosed) & None & 1 & 3 (9 mos) & Yes \\
\hline 5 & Midline basilar tip & None & 4 & 0 (9 mos) & No \\
\hline 6 & Rt ICA & None & 1 & 1 (8 mos) & No \\
\hline 7 & Midline basilar tip & Radiographic ischemic change (MRA) & 0 & 0 (8 mos) & No \\
\hline 8 & Rt ICA & None & 0 & 0 (3 mos) & No \\
\hline 9 & Midline basilar tip & Radiographic ischemic change (MRA) & 0 & 0 (7 mos) & Yes \\
\hline 10 & Rt ACoA & None & 3 & 3 (9 mos) & No \\
\hline 11 & ACoA (thrombosed) & Radiographic \& symptomatic ischemic change (oversized WEB) & 0 & 1 (3 mos) & Yes \\
\hline 12 & Rt MCA proximal & None & 1 & 0 (3 mos) & No \\
\hline 13 & Lt PCoA & Aneurysm rupture from initial coiling attempt & 1 & 1 (3 mos) & No \\
\hline 14 & Midline basilar tip & None & 0 & 0 (3 mos) & No \\
\hline 15 & Midline basilar tip & None & 0 & 0 (6 mos) & No \\
\hline 16 & Lt MCA & Abandoned (rescheduled) & - & - & - \\
\hline 17 & Midline basilar tip & None & 0 & 0 (3 mos) & No \\
\hline 18 & Basilar tip & None & 5 & 1 (3 mos) & No \\
\hline 19 & Lt terminal ICA & Abandoned (coiled) & - & - & - \\
\hline 20 & Lt PCoA & None & 3 & 3 (3 mos) & No \\
\hline 21 & Lt MCA & None & 0 & 0 (3 mos) & No \\
\hline 22 & $\mathrm{ACoA}$ & None & 4 & 4 (3 mos) & No \\
\hline 23 & Rt MCA & None & 0 & 0 (6 mos) & No \\
\hline 24 & Rt PCoA & None & 1 & 1 (6 mos) & No \\
\hline 25 & Midline basilar tip (thrombosed) & None & 4 & 3 (3 mos) & No \\
\hline
\end{tabular}

SX = symptoms; $-=$ unsuccessful WEB insertion.

filling the aneurysm. ${ }^{4}$ This publication was followed by the 2011 publication of a paper by Klisch et al. describing their experience with the WEB DL in 2 patients. ${ }^{10}$ Further case series have provided confidence in the WEB procedure, but the literature is still awaiting long-term experience. Four larger case series within the last 2 years have added experience with the WEB DL from over 100 patients. ${ }^{11,12,16,20}$ The earliest case series, which was published in 2012, was from Pierot et al., who reported on a multicenter clinical study with 21 aneurysms that were treated with the WEB DL device. In this early study it was found that $80 \%$ of patients had satisfactory occlusion of the aneurysm. ${ }^{20}$ In a 2013 publication, Lubicz et al. reported on a series of 19 patients with 20 procedures; they only had 1 complete occlusion. This paper showed the technique to be viable but with a low occlusion rate. ${ }^{11}$ In their 2014 publication, Lubicz et al. reported on a larger series of 45 patients treated with the WEB-DL device. This report showed better clinical results, perhaps proving that placement of the WEB device benefits from experience. The most frequent aneurysm location in their cohort was the MCA, ${ }^{12}$ unlike our study in which basilar aneurysms were most commonly selected for treatment. A recent paper looked at the WEB device in 6 acute cases and found that 2 of the patients had strokes due to the use of an oversized
WEB. ${ }^{2}$ Looking at the Leeds cohort, we also found that the only patient to have a symptomatic ischemic event had an oversized WEB device. We (as suggested in previous papers) cannot emphasize enough how crucial sizing is in the treatment of brain aneurysms with the WEB device. Undersizing can lead to recurrence and residual aneurysm whereas oversizing can lead to clot, vessel occlusion, and thromboembolism. ${ }^{2}$

The biggest multicenter trial to date has emerged from France. This study involved 83 patients with 85 aneurysms. ${ }^{16}$ The complication rate was $10.8 \%$, and complete aneurysm occlusion was noted in $56.9 \%$ of the aneurysms, with an aneurysm remnant in $7.7 \% .{ }^{16} \mathrm{~A}$ standard 3-point aneurysm occlusion scale was used in this study so we cannot assess the occlusion based on the morphology of the WEB device. This paper reported a 1-month mortality rate of $0 \%$ and a morbidity rate of $4 \%$ (2 patients with venous thromboembolism, 1 patient with rupture and venous thromboembolism). The authors reported the morbidity as $1.3 \%$ as two of the strokes had minimal clinical consequence ( $\mathrm{mRS}$ score $<2$ ).

The scale used to assess the WEB device should enable the clinician to appreciate the success of the WEB treatment and subsequently plan future management. It should be graded in such a manner that a gradient of an excel- 
lent result to a poor result can be appreciated. Previously, 3-point scales (such as the Raymond scale) developed for postcoiling aneurysm assessment have been used.11,19,20 Standardization of aneurysm occlusion using the WEB device has been attempted with the 3-point WEB Occlusion Scale (WOS). The WOS is based on the Raymond Scale. ${ }^{5}$ The advantage of this scale is that the agreement between different observers was shown to be excellent. ${ }^{5}$ This is likely due to the simplistic nature of the scale. In addition, this scale allows for comparison with results from coiling. However, when considering publications regarding the WEB device, it becomes obvious that the 3-point scale is not an adequate scoring system. The WEB DL has a proximal and distal basket, and the DL, SL, and SLS all have a proximal recess due to the central proximal concavity of the device. There have been a variety of modifications in scoring from authors looking at the WEB device-for example, a 4-part scale looking at flow immediately after the procedure and then a 3-part scale looking at aneurysm occlusion at follow-up. ${ }^{4,20}$ More recent papers have taken the proximal recess into consideration. ${ }^{2,12}$ However, no scale has considered the occlusion of the proximal and distal basket of the WEB device separately. In the absence of such a scale it is difficult to compare immediate postprocedural angiographic results with follow-up results, and the stages of occlusion using the WEB device cannot be fully appreciated. When considering the WEB device, a poor outcome would be confirmed if there is a neck or aneurysm remnant (Raymond Class 2 or 3, respectively; Leeds Score 4 or 5, respectively). However, if there is a proximal recess remnant, this is caused by the proximal recess of the WEB device and is actually a very good and stable end result. Nevertheless, as it cannot be classed as a complete aneurysm occlusion, it would be graded as a neck remnant in the Raymond scoring system. This falsely implies a poor outcome.

The Leeds scale gives the proximal recess remnant its own classification as Leeds Score 2. If the radiographic picture shows that the distal basket of the WEB is well occluded but the proximal basket shows some filling (note that this only applies to WEB DL devices) this is a good result, as the aneurysm is becoming progressively occluded with slow thrombosis within the WEB device. Also if the WEB device shows slow flow in the proximal and distal basket, further thrombosis is expected over time, and improved results may be expected on follow-up, as seen in our series. Both of these results would receive a score of Class 3 in the Raymond system. Again, this falsely implies a poor outcome and would alert the clinician to the need for rigorous follow-up. The Leeds score gives proximal basket opacification its own score of $3 \mathrm{a}$ and slow flow throughout the WEB a score of 3. In particular the DL and SL devices may cause different immediate angiographic results compared with the late angiographic outcomes. This is particularly true with SL devices that may show slow flow or contrast stagnation at the end of the procedure and subsequently show complete occlusion on follow-up scans. It is important to understand these effects of the WEB device on aneurysms, and operator experience is needed with the use of the device. A neck remnant has a score of 4 on the Leeds scale and is classified as Class 2 on the Raymond scale. An aneurysm remnant has a score of 5 in the Leeds scoring system and is Class 3 on the Raymond scale. Therefore the Leeds scoring system maintains a true gradient from excellent to poor result and enables the clinician to better manage the case and understand the effect of WEB treatment of brain aneurysms.

Within our study, $8(36 \%)$ of 22 patients had complete aneurysm occlusion at follow-up. Satisfactory occlusion (Grade 1-3) was seen in 13 (59\%) of patients. There were 2 (9\%) recurrent aneurysms (Cases 3 and 4). Both cases were performed early in the series of the WEB procedures, and in both a WEB DL was placed.

The HELPS trial, published in 2011, showed a $29 \%$ overall 6-month recurrence rate for coated and bare platinum coil treatment of cerebral aneurysms (24\% for hydrogel-coated and $33 \%$ for bare platinum coil treatment). ${ }^{25}$ The Cerecyte trial, published in 2012, showed that at the 6 -month outcome of Cerecyte-coated and bare platinum coil treatment, approximately $19 \%$ still had aneurysmal sac filling. ${ }^{14}$ The Cerecyte trial also showed that $29 \%$ had complete occlusion and 52\% had a neck remnant at 6-month follow-up. ${ }^{14}$ Although rarely performed in modern practice, if the expertise is available, then microsurgical clipping of basilar tip aneurysms can yield high occlusion rates and an acceptably low complication rate. 8,15 The ISAT has shown that the complication rate is lowered if simple endovascular coiling is possible. ${ }^{13}$ However, careful consideration of treatment strategy is needed for complex difficult aneurysms that cannot be treated with standard coiling methods.

At follow-up ( $\geq 3$ months), 3 patients exhibited radiographic cerebral ischemic changes, and 1 patient presented with hydrocephalus secondary to recurrence. Only 2 of these patients were symptomatic (see Table 5), resulting in a morbidity rate of $9.1 \%$ ( 2 of 22 patients). The mortality rate was $0 \%$ in our series. Early in the experience of WEB placement, no standard additional anticoagulation was given before or after the procedure. However 3 patients treated early in our experience had radiological evidence of thromboembolism, so later patients received a standard 6 weeks of aspirin treatment (75 mg per day) after the procedure. In addition, some patients were administered $500 \mathrm{mg}$ of it intravenously; these patients also followed the 6-week oral aspirin regimen.

The CLARITY study (published in 2012) showed that the risk of a thromboembolic event from endovascular treatment of ruptured aneurysms is almost doubled if the patient has an aneurysm neck wider than $4 \mathrm{~mm} .{ }^{17}$ The ATENA trial looked at the treatment of 739 coiled unruptured intracranial aneurysms, and $7 \%$ of the patients had a thromboembolic event. ${ }^{21}$ In the patient cohort of the CLARITY trial, $20.8 \%$ of patients with an aneurysm neck greater than $4 \mathrm{~mm}$ had a thromboembolic event (compared with $11 \%$ if the neck is equal to or below $4 \mathrm{~mm}$ ). ${ }^{17}$ Larger case series are needed to better assess the risk of a thromboembolic event due to placement of a WEB device. At present, however, it would be advisable to provide shortterm postprocedural treatment (e.g., 6 weeks) with an antiplatelet agent in addition to intraprocedural heparin.

In our study, 2 patients had a recurrent aneurysm (Cases 4 and 3). It is worth noting that the patient in Case 4 had 
a large thrombosed aneurysm, which was not suitable for stent treatment due to the patient's noncompliance with medical treatment. This patient was treated again (Case $25)$ with a further WEB and additional coiling. It is likely that thrombosis causes movement of the WEB within the aneurysm and a less satisfactory long-term result (the patients in Cases 1 and 11 also had residual aneurysm at follow-up). The other patient with a recurrence (Case 3) is currently under observation. In 1 difficult case, a stent was placed in addition to a WEB device, producing excellent results. This has prompted consideration that stent placement as an adjunct to WEB device placement might be a possible alternative treatment for the large, partially thrombosed aneurysm. We suggest that the WEB device as a solitary treatment option is not advisable for thrombosed aneurysms.

This study is a retrospective study of all patients treated with the WEB device at our center during a single year. All of the patients had aneurysms that were considered too technically difficult for coil embolization as a sole treatment. In most of these cases, $\mathrm{Y}$ stenting or $\mathrm{T}$ stenting would have been required to protect the aneurysm. The WEB device can be superior in these cases as no longterm antiplatelet therapy is needed and the procedure time is shorter. The advantage of our study is that we have included both the WEB DL and the newer SL and SLS devices. The WEB was originally designed for bifurcation aneurysms. The newer SL and SLS make using the WEB device for a sidewall aneurysm more feasible. This is because it is easier to deploy a smaller microcatheter such as the Headway (Terumo Medical Corporation) or the VIA (Sequent Medical) with the SL or SLS. In addition, the SL and SLS devices have a high success rates with outcomes comparable to those achieved with the WEB DL. In this study it was noted that none of the 8 patients treated with SL or SLS had a residual aneurysm at follow-up. To date only 1 small study of 6 acute patients in the literature has mentioned utilization of the SL device. ${ }^{2}$ In our study 4 patients had a WEB SL device placed and 4 had a WEB SLS. We postulate that the SL and SLS are likely to be the future of the WEB device.

This is the first WEB publication using the new specifically tailored Leeds WEB aneurysm occlusion scale to enhance accuracy and reproducibility of results. It is indisputable that the current pace of innovation within this field is rapid. Given the speed of progress, the paucity of the literature makes even smaller series important for evidencebased practice. The limitation of this study is that due to the recent introduction of the WEB device to aneurysm embolization, we have no long-term results. These results will be gathered over future years; larger multicenter studies are needed.

\section{Conclusions}

This WEB has shown itself to be a promising new approach with the potential to increase the scope of treatment for difficult wide-necked complex bifurcation aneurysms. Overall, the results appear to compare favorably with the results of coil embolization, with minimal risk of complication and morbidity and mortality. WEB treat- ment will reduce the need for complex stent systems in difficult aneurysm treatment and facilitate safe, quick, and effective treatment of these lesions. Long-term results and efficacy need to be assessed with an appropriately devised scoring system.

\section{References}

1. Banks JL, Marotta CA: Outcomes validity and reliability of the modified Rankin scale: implications for stroke clinical trials: a literature review and synthesis. Stroke 38:10911096, 2007

2. Caroff J, Mihalea C, Dargento F, Neki H, Ikka L, Benachour N, et al: Woven Endobridge (WEB) Device for endovascular treatment of ruptured intracranial wide-neck aneurysms: a single-center experience. Neuroradiology 56:755-761, 2014

3. Chalouhi N, Starke RM, Koltz MT, Jabbour PM, Tjoumakaris SI, Dumont AS, et al: Stent-assisted coiling versus balloon remodeling of wide-neck aneurysms: comparison of angiographic outcomes. AJNR Am J Neuroradiol 34:19871992, 2013

4. Ding YH, Lewis DA, Kadirvel R, Dai D, Kallmes DF: The Woven EndoBridge: a new aneurysm occlusion device. AJNR Am J Neuroradiol 32:607-611, 2011

5. Fiorella D, Arthur A, Byrne J, Pierot L, Molyneux A, Duckwiler $\mathrm{G}$, et al: Interobserver variability in the assessment of aneurysm occlusion with the WEB aneurysm embolization system. J Neurointerv Surg 7:591-595, 2015

6. Guglielmi G, Viñuela F, Dion J, Duckwiler G: Electrothrombosis of saccular aneurysms via endovascular approach. Part 2: Preliminary clinical experience. J Neurosurg 75:8-14, 1991

7. Guglielmi G, Viñuela F, Sepetka I, Macellari V: Electrothrombosis of saccular aneurysms via endovascular approach. Part 1: Electrochemical basis, technique, and experimental results. J Neurosurg 75:1-7, 1991

8. Hernesniemi J, Korja M: At the apex of cerebrovascular surgery-basilar tip aneurysms. World Neurosurg 82:37-39, 2014

9. Hong Y, Wang YJ, Deng Z, Wu Q, Zhang JM: Stent-assisted coiling versus coiling in treatment of intracranial aneurysm: a systematic review and meta-analysis. PLoS One 9:e82311, 2014

10. Klisch J, Sychra V, Strasilla C, Liebig T, Fiorella D: The Woven EndoBridge cerebral aneurysm embolization device (WEB II): initial clinical experience. Neuroradiology 53:599-607, 2011

11. Lubicz B, Mine B, Collignon L, Brisbois D, Duckwiler G, Strother C: WEB device for endovascular treatment of wideneck bifurcation aneurysms. AJNR Am J Neuroradiol 34:1209-1214, 2013

12. Lubicz B, Klisch J, Gauvrit JY, Szikora I, Leonardi M, Liebig T, et al: WEB-DL endovascular treatment of wide-neck bifurcation aneurysms: short- and midterm results in a European study. AJNR Am J Neuroradiol 35:432-438, 2014

13. Molyneux A, Kerr R, Stratton I, Sandercock P, Clarke M, Shrimpton J, et al: International Subarachnoid Aneurysm Trial (ISAT) of neurosurgical clipping versus endovascular coiling in 2143 patients with ruptured intracranial aneurysms: a randomised trial. Lancet 360:1267-1274, 2002

14. Molyneux AJ, Clarke A, Sneade M, Mehta Z, Coley S, Roy $\mathrm{D}$, et al: Cerecyte coil trial: angiographic outcomes of a prospective randomized trial comparing endovascular coiling of cerebral aneurysms with either Cerecyte or bare platinum coils. Stroke 43:2544-2550, 2012

15. Nanda A, Sonig A, Banerjee AD, Javalkar VK: Microsurgical management of basilar artery apex aneurysms: a single surgeon's experience from Louisiana State University, Shreveport. World Neurosurg 82:118-129, 2014 
16. Papagiannaki C, Spelle L, Januel AC, Benaissa A, Gauvrit JY, Costalat V, et al: WEB intrasaccular flow disruptorprospective, multicenter experience in 83 patients with 85 aneurysms. AJNR Am J Neuroradiol 35:2106-2111, 2014

17. Pierot L, Cognard C, Anxionnat R, Ricolfi F: Ruptured intracranial aneurysms: factors affecting the rate and outcome of endovascular treatment complications in a series of 782 patients (CLARITY study). Radiology 256:916-923, 2010

18. Pierot L, Cognard C, Spelle L, Moret J: Safety and efficacy of balloon remodeling technique during endovascular treatment of intracranial aneurysms: critical review of the literature.

AJNR Am J Neuroradiol 33:12-15, 2012

19. Pierot L, Klisch J, Cognard C, Szikora I, Mine B, Kadziolka $\mathrm{K}$, et al: Endovascular WEB flow disruption in middle cerebral artery aneurysms: preliminary feasibility, clinical, and anatomical results in a multicenter study. Neurosurgery 73:27-35, 2013

20. Pierot L, Liebig T, Sychra V, Kadziolka K, Dorn F, Strasilla $\mathrm{C}$, et al: Intrasaccular flow-disruption treatment of intracranial aneurysms: preliminary results of a multicenter clinical study. AJNR Am J Neuroradiol 33:1232-1238, 2012

21. Pierot L, Spelle L, Vitry F: Immediate clinical outcome of patients harboring unruptured intracranial aneurysms treated by endovascular approach: results of the ATENA study. Stroke 39:2497-2504, 2008

22. Rankin J: Cerebral vascular accidents in patients over the age of 60. II. Prognosis. Scott Med J 2:200-215, 1957

23. Roy D, Milot G, Raymond J: Endovascular treatment of unruptured aneurysms. Stroke 32:1998-2004, 2001

24. van Swieten JC, Koudstaal PJ, Visser MC, Schouten HJ, van
Gijn J: Interobserver agreement for the assessment of handicap in stroke patients. Stroke 19:604-607, 1988

25. White PM, Lewis SC, Gholkar A, Sellar RJ, Nahser H, Cognard C, et al: Hydrogel-coated coils versus bare platinum coils for the endovascular treatment of intracranial aneurysms (HELPS): a randomised controlled trial. Lancet 377:1655-1662, 2011

\section{Disclosure}

Dr. Goddard reports receiving financial support from Sequent Medical to attend a medical meeting (ESMINT). Dr. Patankar reports being a proctor for WEB treatment.

\section{Author Contributions}

Conception and design: Patankar, Lawson. Acquisition of data: Patankar, Lawson, Goddard. Analysis and interpretation of data: Patankar, Lawson. Drafting the article: Patankar, Lawson. Critically revising the article: Patankar, Lawson. Reviewed submitted version of manuscript: all authors. Approved the final version of the manuscript on behalf of all authors: Patankar. Administrative/ technical/material support: Patankar, Lawson. Study supervision: Patankar.

\section{Correspondence}

Tufail Patankar, Department of Neurosurgery, Leeds Teaching Hospitals NHS Trust, Great George St., Leeds LS1 3EX, United Kingdom. email: tufail.patankar@leedsth.nhs.uk. 